Research Article

\title{
Evaluating Fly Ash-Based Geopolymers as a Modifier for Asphalt Binders
}

\author{
Abdulrahman Hamid $\mathbb{D}^{1},{ }^{1}$ Hamed Alfaidi, ${ }^{1}$ Hassan Baaj $\mathbb{D}^{1},{ }^{1}$ and Mohab El-Hakim $\mathbb{D}^{1,2}$ \\ ${ }^{1}$ Department of Civil and Environmental Engineering, University of Waterloo, Waterloo, Canada N2L 3G1 \\ ${ }^{2}$ Department of Civil and Environmental Engineering, Manhattan College, Bronx, NY, USA \\ Correspondence should be addressed to Hassan Baaj; hassan.baaj@uwaterloo.ca
}

Received 29 May 2019; Revised 3 September 2019; Accepted 16 September 2019; Published 19 February 2020

Academic Editor: María Criado

Copyright (c) 2020 Abdulrahman Hamid et al. This is an open access article distributed under the Creative Commons Attribution License, which permits unrestricted use, distribution, and reproduction in any medium, provided the original work is properly cited.

\begin{abstract}
Severe Canadian winter conditions and growing traffic volumes are vital factors resulting in a reduction of the service life of flexible pavements. Researchers and engineers strived to develop several additives to develop balanced asphalt mixers capable of resisting distresses that caused deterioration of flexible pavements in Canada. In this study, a critical literature review regarding the use of geopolymers and their application in construction materials is provided. Moreover, an experimental matrix of laboratory testing was conducted to study the rheological and microstructural properties of the PG 58-28 asphalt binder, with different percentages $(0 \%, 3 \%, 6 \%$, and $9 \%)$ of geopolymer. The effect of geopolymer-curing time on rheological properties was investigated. Rotational viscometer, dynamic shear rheometer (DSR), and environmental scanning electron microscopy (ESEM) imaging devices were used to compare the performance of control binder with a binder with different percentages of geopolymers. Results indicated that the increase in the geopolymer content and the curing time affect the rheological behavior of the asphalt binder by increasing its viscosity, complex shear modulus, and failure temperature. Samples with higher geopolymer percentage exhibited better performance in terms of rutting resistance. Moreover, an increase in the failure temperature of modified asphalt binder with $9 \%$ geopolymer is recorded as $8.58 \%, 14.2 \%$, and $15.2 \%$ for curing times of 2,7 , and 14 days, respectively, compared with virgin asphalt. Furthermore, the nanoparticles appear to be well dispersed in the binder, and increasing the percentage of the geopolymer does not seem to affect the microstructure of the binder. Overall research conclusion is that geopolymer application resulted in a potential enhancement of some of the properties of the asphalt binder.
\end{abstract}

\section{Introduction}

Modified asphalt binder could be used to reduce pavement distresses such as rutting and cracking. Polymer modification of asphalt binder could be a cost-effective solution to reduce the annual budget for maintenance and rehabilitation of flexible pavements. In the past two decades, growth in the use of polymer-modified asphalt binders in pavement-engineering applications was noticed. Significant improvement of the mechanical and rheological properties of the asphalt binder at different temperatures was reported in the literature [1-3]. Polymers can be defined as large molecules with numerous compositions of small molecules bonded together. These small molecules are called monomers [4]. The binder modification using polymers increases the sustainability of asphalt binders and asphalt mix designs. In addition, performance enhancement and cost reductions are achieved through polymer modification of asphalt binders [5]. Application of modifiers in asphalt binders would result in a reduction of optimum binder content, increasing stability, increasing the bond between asphalt cement and aggregates, and improving density [6]. In addition, modifiers would minimize the environmental impact on roads, such as traffic noise, the total expenditure for repair, and maintenance of road structures.

Scholars investigated the use of waste materials to improve the performance of asphalt binders. Numerous studies have been conducted to evaluate the benefits of using crumb rubber [7, 8], cylinder oil [9], and palm oil fuel ash (POFA) $[10]$ as binder modifiers. Geopolymer-modified binder is a 
new method to capitalize on the use of waste materials in paved roads. Geopolymer concept was first introduced by Davidovits in 1978 [11]. The geopolymers are inorganic polymers with aluminosilicate base. The geopolymers are produced from the interaction between pozzolanic materials with an alkaline solution such as sodium hydroxide $(\mathrm{NaOH})$ and sodium silicate $\left(\mathrm{Na}_{2} \mathrm{SiO}_{3}\right)$, or potassium hydroxide $(\mathrm{KOH})$ and potassium silicate $\left(\mathrm{K}_{2} \mathrm{SiO}_{3}\right)$ [12]. Materials stemming from solid wastes and by-products endowed with silica and/or aluminas such as fly ash, red mud, mine waste, and blast furnace slag qualify as a pozzolanic component of geopolymerization [13]. Geopolymer has also proven its ability to develop mechanical properties rapidly, to improve the high fire-resistance property, and to reduce energy consumption and greenhouse emissions [14-17]. Geopolymer has many applications in the field of manufacturing such as in the aerospace and automobile, metallurgy and nonferrous foundries, civil engineering, and plastic industries [18]. Geopolymeric materials are used in toxic waste management because of their ability to absorb toxic chemical wastes [18].

During the past two decades, geopolymers were widely used as an environment-friendly additive to cementitious construction materials. Geopolymers were noted to reduce the $\mathrm{CO}_{2}$ emissions associated with the production of cementitious materials [19]. Geopolymer can also be used in fire-resistant wall panels [13], masonry units, protective coatings, and repairs materials, shotcrete, and high-performance fiber reinforced laminates [15]. Sumajouw et al. [20] investigated the structural behavior of geopolymer concrete columns and noted that the possibility of using the current concrete design standers for fly ash-based geopolymer concrete columns. Twelve columns were tested under axial load and uniaxial bending in the mode of single curvature during this investigation. Six columns were characterized by $40 \mathrm{MPa}$ compressive strength, while the rest had $60 \mathrm{MPa}$ compressive strength. Different reinforcement ratios and load eccentricities were considered. Load carrying capacity, deflection characteristic, and mode of failure were determined. Results showed that the current concrete design standards could be used for designing fly ash-based geopolymer concrete columns.

Geopolymers have many applications in the field of soil stabilization. Recent studies investigated the effectiveness of using geopolymer to improve the physical and mechanical properties of soils. Cristelo et al. [21] experimentally studied the effectiveness of geopolymer on the improvement of rammed-earth construction soils. The ratio of liquid to solid, the ratio of $\mathrm{Na}_{2} \mathrm{O}$ to ash, and the alkali concentration were investigated through this study. Furthermore, the influence of concrete superplasticizer, sodium chloride, and calcium hydroxide is also discussed. The results showed that there are only slight effects of sodium chloride or superplasticizer, and there is a significant increase in compressive strength as an optimum value for the ratio of activator: solids and the concentration of alkali. Sukmak et al. [22] investigated the important factors such as sample sizes, heating conditions, and different percentages of silty clay and fly ash that affect the strength development in clay-fly ash geopolymer brick.
In this study, sodium hydroxide and sodium silicate were used as an alkaline activator, and fly ash was used as a pozzolanic material. The results showed that the samples with optimum heat energy per weight $(\mathrm{E} / \mathrm{W})$ is $8.5^{\circ} \mathrm{C} \mathrm{h} / \mathrm{g}$ for fly ash/clay ratios of 0.3 and 0.5 whereas the $\mathrm{E} / \mathrm{W}$ is $7.57^{\circ} \mathrm{C} \mathrm{h} /$ $\mathrm{g}$ for fly ash/clay ratio of 0.7 . Moreover, they recommended that a substantial relationship between weight and heat energy should be considered in the bricks production industry.

Recently, geopolymer was used as an additive during the preparation of warm mix asphalt. Tang et al. [23] studied the applications of geopolymer in warm mix asphalt. Sodium hydroxide and sodium silicate were used with different concentrations as an activator for aluminosilicate in metakaolin, slag, and silica fume. The results showed that geopolymer could decrease the mixing temperature. Consequently, geopolymers could be used to reduce warm mix asphalt mixing cost.

The need for new additive with high properties is in continuous growth to enhance the asphalt binder properties. The use of by-product materials such as fly ash enhances the sustainability of pavement mixtures and reduces the emission of $\mathrm{CO}_{2}$. Fly ash can be divided into three classes, N, F, and C, based on its composition and source of origin [24]. The concentration of calcium in fly ash has an effective influence on the polymerization process which was noted that fly ash with a low amount of calcium such as Class $F$ is better for the formation of geopolymers than fly ash with a high amount of calcium such as Class C [25]. Xu and van Deventer [26] noted that the addition of sodium hydroxide solution to the sodium silicate solution as the alkaline liquid improved the reaction with fly ash.

The main objective of this project is to study the rheological behavior and performance grading of geopolymermodified binder with the concentrations of $3 \%, 6 \%$, and $9 \%$ at different temperatures using several laboratory experiments. The impact of curing time variation on the performance of geopolymer was also evaluated in this project. Finally, the microstructure of base and modified asphalt binder was investigated using the environmental scanning electron microscope (ESEM).

\section{Experimental Methods}

\subsection{Materials}

2.1.1. Geopolymer Preparation. Geopolymer was the combination of fly ash and the alkali activator. The alkali activator was sodium silicate solution $\left(\mathrm{Na}_{2} \mathrm{SiO}_{3}\right)$ and sodium hydroxide $(\mathrm{NaOH})$ pallet diluted in water to produce 8 Molar $(8 \mathrm{M}) \mathrm{NaOH}$ solution. A mixture of sodium silicate solution and sodium hydroxide solution was prepared to activate the alumino-silicate precursors in fly ash.

In this study, fly ash with Class $\mathrm{F}$ is used which satisfies this chemical composition $\mathrm{SiO}_{2}+\mathrm{Al}_{2} \mathrm{O}_{3}+\mathrm{Fe}_{2} \mathrm{O}_{3} \geq 70 \%$ according to the ASTM C618-17a [24]. The chemical compositions of fly ash are listed in Table 1. Geopolymer 
Table 1: Chemical Composition (\%) of Fly ash.

\begin{tabular}{lccccccc}
\hline Constituent (\%) & $\mathrm{SiO}_{2}$ & $\mathrm{Al}_{2} \mathrm{O}_{3}$ & $\mathrm{Fe}_{2} \mathrm{O}_{3}$ & $\mathrm{CaO}$ & $\mathrm{MgO}^{2}$ & $\mathrm{SO}_{3}$ & $\mathrm{Na}_{2} \mathrm{O}$ \\
\hline Fly ash & 57.2 & 23.5 & 3.8 & 9.3 & 1.0 & 0.2 & 2.43 \\
\hline
\end{tabular}

additives were prepared using the alkaline medium as the chemical activator and fly ash as the aluminosilicate source.

Figure 1 shows the adopted mixing procedure to prepare the geopolymer. The following steps summarize the preparation of geopolymer:

(1) Prepared alkaline solution using sodium hydroxide $(8 \mathrm{M})$ and sodium silicate solution with percentages of $100: 50 \%$ by mass respectively.

(2) 200 grams of fly ash powder was mixed with 80 grams of the alkaline medium for 6 minutes.

(3) The formed slurry was transferred to silicon molds, as shown in Figure 1.

(4) Geopolymers were cured at room temperature $\left(23-25^{\circ} \mathrm{C}\right)$ and in the oven $\left(40^{\circ} \mathrm{C}\right)$. Curing was performed in three different curing plans which will be explained in the following section.

In this study, there are three sets of geopolymer prepared based on the curing time as the following: (i) first set was cured for 24 hours at room temperature and then cured in the oven at $40^{\circ} \mathrm{C}$ for 24 hours, (ii) second set was cured for 6 days at room temperature and then cured in the oven at $40^{\circ} \mathrm{C}$ for 24 hours, and (iii) third set was cured for 13 days at room temperature and then cured in the oven at $40^{\circ} \mathrm{C}$ for 24 hours. The particles size greater than $0.25 \mathrm{~mm}$ may impact the consistency of results obtained from tests such as DSR. Therefore, geopolymer samples were grinded into powder, as shown in Figure 1 and then were sieved using sieve No. 100 to avoid particles with a diameter of more than $0.15 \mathrm{~mm}$.

2.1.2. Modified Binder Preparation. The base asphalt binder used was PG 58-28, and the properties of the virgin asphalt binder are shown in Table 2 . The base asphalt binder of $300 \mathrm{~g}$ was heated until it becomes fluid then the geopolymer was added into the base asphalt blend with doses of $3 \%, 6 \%$, and $9 \%$ by mass of the asphalt binder. Subsequently, the blends were mixed using a mechanical shear mixer for 120 minutes under a speed of $2000 \mathrm{r} / \mathrm{min}$ with a temperature of $150^{\circ} \mathrm{C} \pm 5$ to produce a homogenous blend, as depicted in Figure 2.

\section{Experimental Test Procedures}

3.1. Rotational Viscometer Test. The viscosity of virgin and modified asphalt binder was measured using the rotational viscometer with $10 \mathrm{~g}$ of asphalt binder. Three readings were determined for each test temperature, and the average was recognized as the test result. Also, the test temperatures ranged from $90^{\circ} \mathrm{C}$ to $165^{\circ} \mathrm{C}$ and using $15^{\circ} \mathrm{C}$ as an interval.

3.2. Dynamic Shear Rheometer (DSR) Test. The dynamic shear rheometer (DSR) is used to study the rheological behavior of asphalt binder at intermediate and high temperatures. Moreover, DSR measures the complex shear modulus $\left(G^{*}\right)$ and the phase angle $(\delta)$ of asphalt binder at different temperatures and frequencies of loading, as per AASHTO T315. In this study, DSR-frequency sweep test was performed for the virgin and modified binders using a 25 $\mathrm{mm}$ and 8 - $\mathrm{mm}$ diameter plate and a $1 \mathrm{~mm}$ and $2 \mathrm{~mm}$ gap, respectively. The tests were performed at sixteen frequencies ranging from $0.159 \mathrm{~Hz}$ to $15 \mathrm{~Hz}$ while the test temperatures ranged from 11 to $35^{\circ} \mathrm{C}$ (intermediate temperature) and from 40 to $64^{\circ} \mathrm{C}$ (high temperature). In this study, sinusoidal shear strains were conducted on asphalt binder samples by placing the samples between two parallel plates, one plate is fixed, and another one is moving freely. Then, the various frequencies are applied under several temperatures. Sinusoidally changing shear strain is expressed as $[27,28]$

$$
\gamma(t)=\gamma_{0} \sin \omega t
$$

with resulting stress

$$
\tau(t)=\tau_{0} \sin (\omega t+\delta)
$$

where $\gamma_{0}$ is the peak strain, $\tau_{0}$ is the peak stress, $\omega$ is the radian frequency, $\delta$ is the phase angle, and $t$ is the time.

After changing the phase by $\pi / 2$,

$$
\begin{aligned}
& \gamma^{*}=\gamma_{0} e^{i \omega t}, \\
& \tau^{*}=\tau_{0} e^{i(\omega t+\delta)} .
\end{aligned}
$$

Then, the complex shear modulus is determined by the following equation:

$$
\begin{aligned}
G^{*} & =G^{\prime}+i G^{\prime \prime}=\frac{\tau^{*}}{\gamma^{*}}=\frac{\tau_{0} e^{i(\omega t+\delta)}}{\gamma_{0} e^{i \omega t}}=\left(\frac{\tau_{0}}{\gamma_{0}}\right) e^{i \delta} \\
& =\left(\frac{\tau_{0}}{\gamma_{0}}\right)(\cos \delta+\sin \delta) .
\end{aligned}
$$

Equation (4) shows that

$$
\begin{aligned}
\left|G^{*}\right| & =\frac{\tau_{0}}{\gamma_{0}}=\sqrt{G^{\prime 2}+G^{\prime \prime 2}}, \\
G^{\prime} & =\left|G^{*}\right| \cos \delta
\end{aligned}
$$

which is called storage modulus,

$$
G^{\prime \prime}=\left|G^{*}\right| \sin \delta,
$$

which is called loss modulus.

$$
\tan \delta=\frac{G^{\prime \prime}}{G^{\prime}} .
$$

The DSR results were used to construct the master curves, isochronal plots, and rutting figures. Also, the failure temperatures were also determined from the DSR-grading test. The development of the master curve helps to make a comparison between the stiffness of asphalt binder over different ranges of temperatures and frequencies. In order to obtain the master curve, a shift factor should be applied to 


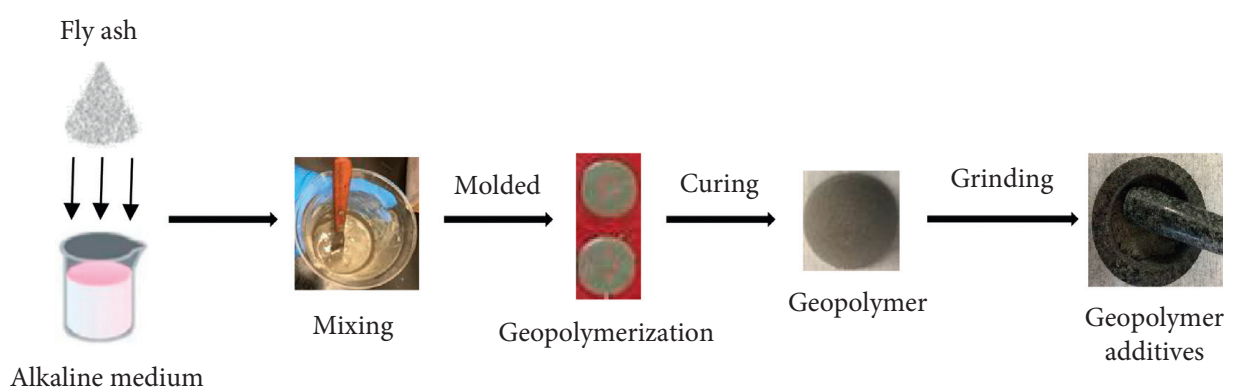

FIgURE 1: Preparation of geopolymer additives.

TABle 2: Properties of original asphalt binder.

\begin{tabular}{lcccc}
\hline Index & $\begin{array}{c}\text { Conditions } \\
\left({ }^{\circ} \mathrm{C}\right)\end{array}$ & Unit & Results & Requirements \\
\hline Specific gravity & At 15 & & 1.03 & - \\
Brookfield viscosity & At 135 & $\mathrm{~Pa} \cdot \mathrm{s}$ & 0.275 & $3.0 \mathrm{max}$ \\
Flash point & - & ${ }^{\circ} \mathrm{C}$ & $230+$ & $230 \mathrm{~min}$ \\
$G^{*} / \sin (\delta)$ & At 58 & $\mathrm{kPa}$ & 1.195 & $1.0 \mathrm{~min}$ \\
\hline
\end{tabular}

the experimental complex modulus $\left(G^{*}\right)$ and phase angle $(\delta)$ values in order to normalize them to a reference temperature. The master curve can be developed using a specified reference temperature and applying a relationship between complex modulus and frequency [29].

\subsection{Environmental Scanning Electron Microscopy (ESEM).} ESEM is a microscope that uses high-pressure gas in a chamber to examine a relatively natural state in which materials are scanned analogously to a standard SEM without routine preparation for compatibility [30]. The model of ESEM unit used to test the specimens was FEI Quanta 250 FEG, as shown in Figure 3.

A stainless-steel sample mold design was developed recently in the Centre for Pavement and Transportation Technology (CPATT) with an $8 \mathrm{~mm}$ diameter [31], as depicted in Figure 3.

\section{Results and Discussion}

4.1. Effects of Geopolymer on Viscosity. The rotational viscosity of asphalt binder is considered an important index to assess the workability for asphalt binder. Hence, determination of the adequate asphalt binder mixing temperature and compaction is significantly impacted by the geopolymer content. The percentage of geopolymers significantly affects the viscosity of the asphalt binder [23]. Figures 3 and 4 show the average viscosity of asphalt binder with different percentages of geopolymer $(0,3,6$, and $9 \%$ ).

The virgin binder was characterized by the lowest viscosity, whereas the modified asphalt binder sample with $9 \%$ of geopolymer has the highest viscosity which indicates that $9 \%$ of geopolymer has better performance regarding rutting resistance. However, using the statistical $T$-test to compare the viscosity of virgin binder and binder with $9 \%$ geopolymer at temperatures ranging from $90^{\circ} \mathrm{C}$ to $165^{\circ} \mathrm{C}$ resulted in the insignificant difference at $95 \%$ confidence level with a $P$-value of 0.126 . It was noted that the viscosity of the $9 \%$ modified binder was higher than that of the virgin binder by $51 \%$ at $90^{\circ} \mathrm{C}$. The difference between the viscosity of the two binders vanishes at higher temperatures as shown in Figure 4.

The increase in binder viscosity due to the addition of geopolymer materials was reported by previous scholars $[1,28,32]$. Asphalt binders with high viscosity achieve excellent weather resistance and provide strong binding forces between aggregates. In addition, asphalt binders with high viscosity have better resistance to displacement by water than those of low viscosity [33]. The viscosity results of asphalt binder with 3,6, and 9\% geopolymer content fell below the maximum limit of $3 \mathrm{~Pa} \cdot \mathrm{s}$ at the temperature of $135^{\circ} \mathrm{C}$ according to the Superpave specifications.

Figure 5 shows the viscosity of asphalt binder samples with $9 \%$ geopolymer and conditioned at curing times of 2 , 7 , and 14 days. Figure 6 presents the viscosity data through two stages. In stage one, the viscosity of both virgin and modified binders with various curing times was subjected to immediate reduction as the temperature increased from 90 to $120^{\circ} \mathrm{C}$. The highest viscosity was noted in the modified binder with 7- and 14-day curing time. Stage two witnessed a temperature change from $120^{\circ} \mathrm{C}$ to $165^{\circ} \mathrm{C}$. The results of stage two show that the modified binders still were characterized by higher viscosity compared with the virgin binder.

The statistical analysis of the $9 \%$ geopolymer-modified binder confirmed that the curing time period does not have a significant impact on the viscosity. The 2-day curing period was considered the control curing period. The 7-day and 14day curing period viscosity results were compared with the 2-day curing period to check the impact of curing period on viscosity. The statistical $T$-test resulted in $P$-values of 0.19 and 0.2 for the viscosity of 7-day and 14-day curing periods compared with the control curing period (2-days). Therefore, the additional curing time has an insignificant impact on viscosity. It should be noted that the percentage increase in viscosity was $30 \%$ by increasing the curing period from 2 to 7 days. The viscosity showed $0 \%$ change between 7 and 14 day curing periods. Therefore, extending the curing period beyond 7 days will not result in a significant change in the 


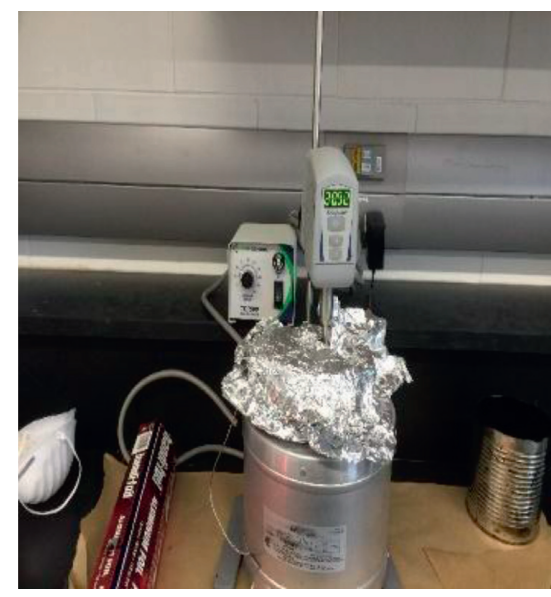

(a)

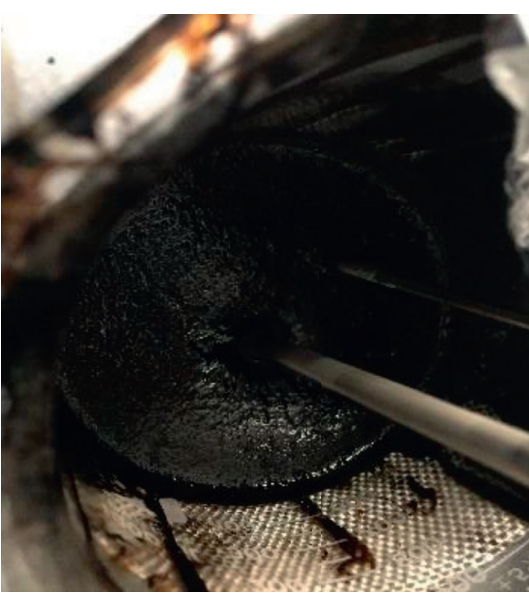

(b)

Figure 2: Mechanical shear mixer.

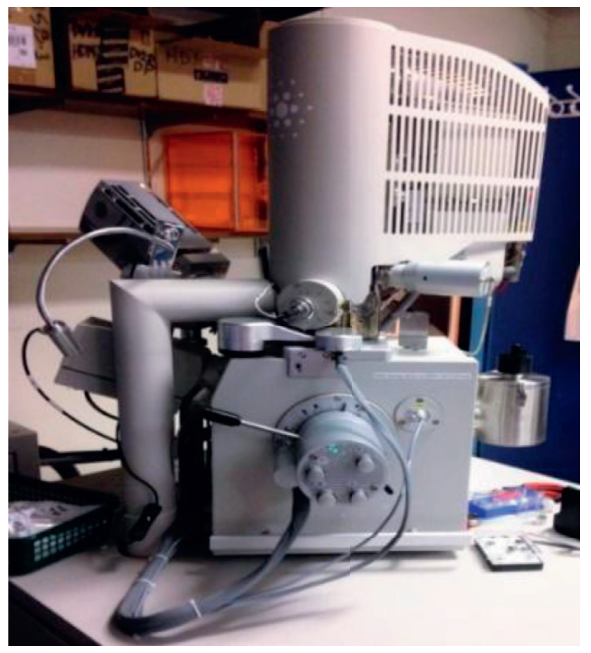

(a)

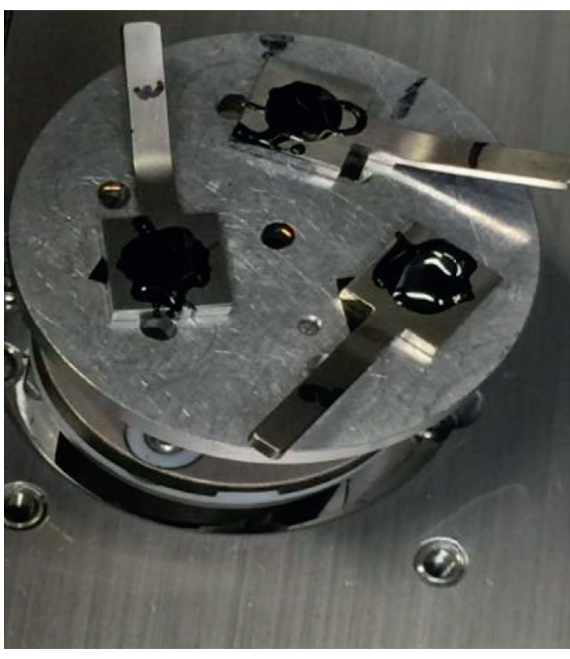

(b)

FIgURE 3: ESEM device (a) and sample mould with binder in the ESEM stage (b).

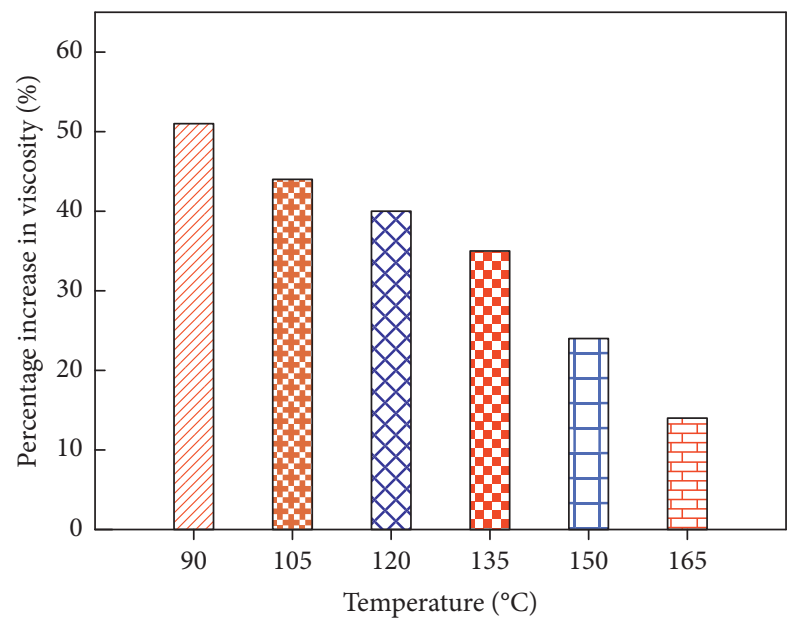

Figure 4: Percentage increase of viscosity comparing the $9 \%$ polymer-modified binder to the virgin binder. viscosity of geopolymer modified binders, which confirms the findings from $[13,17,34,35]$.

\subsection{Effects of Geopolymer on Rheological Properties}

4.2.1. Rheological Master Curve. Figures 7(a) and 7(b) present the rheological master curve at a reference temperature of $35^{\circ} \mathrm{C}$ for complex shear modulus and phase angle. Figure $7(\mathrm{a})$ showed the insignificant difference between the complex shear modulus of modified asphalt binder with 6 and 9\% of geopolymer. Airey [1] studied the rheological behavior of styrene butadiene styrene (SBS) modified binder with $3 \%, 5 \%$, and $7 \%$ of geopolymer and reported an increase in complex shear modulus with increasing the modifier percentages. Based on results obtained from specimens tested in CPATT, an increase of geopolymer percentage above $6 \%$ did not have a significant impact on 


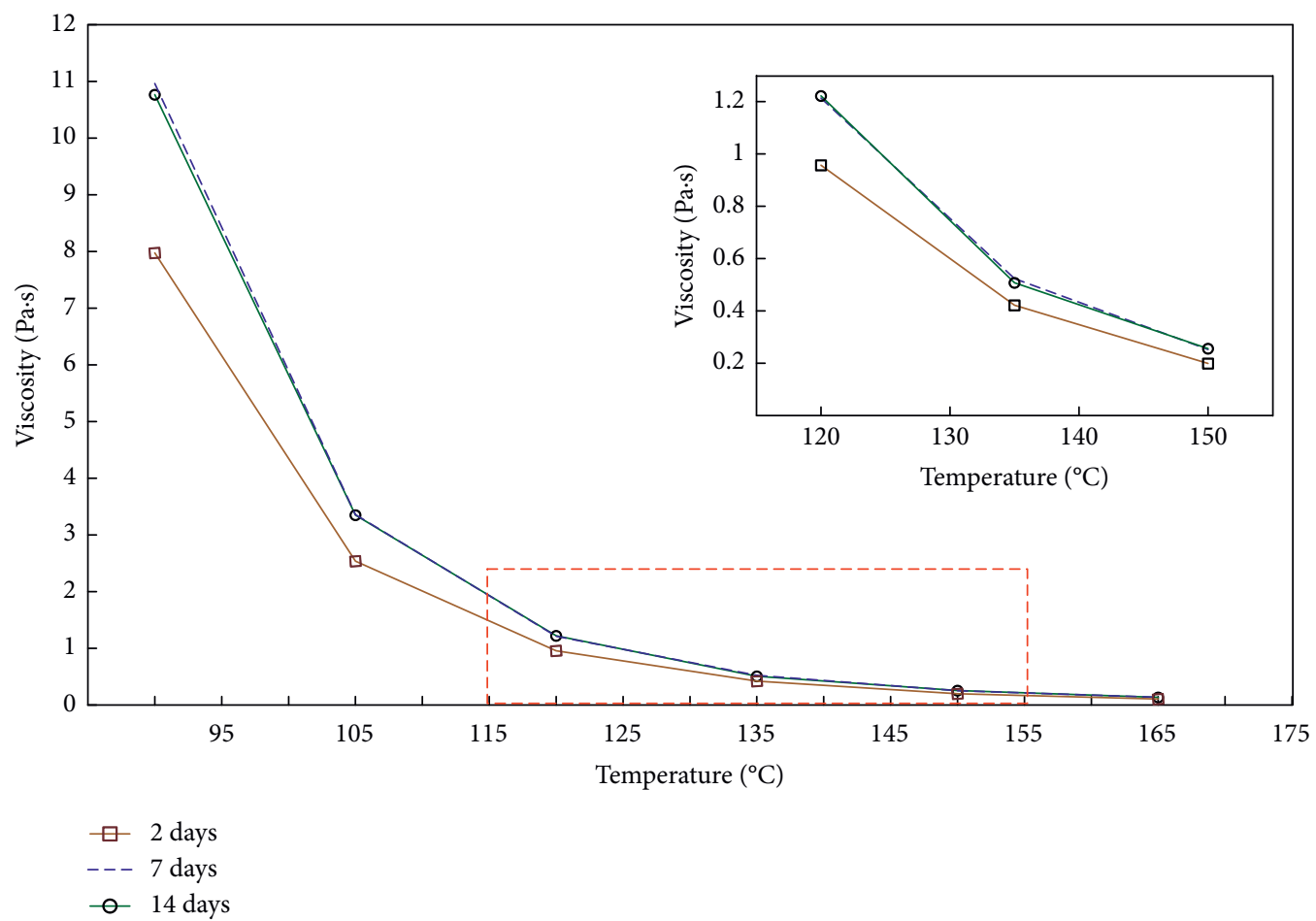

FIgURE 5: Effects of curing time on asphalt binder viscosity for $9 \%$ of geopolymer.

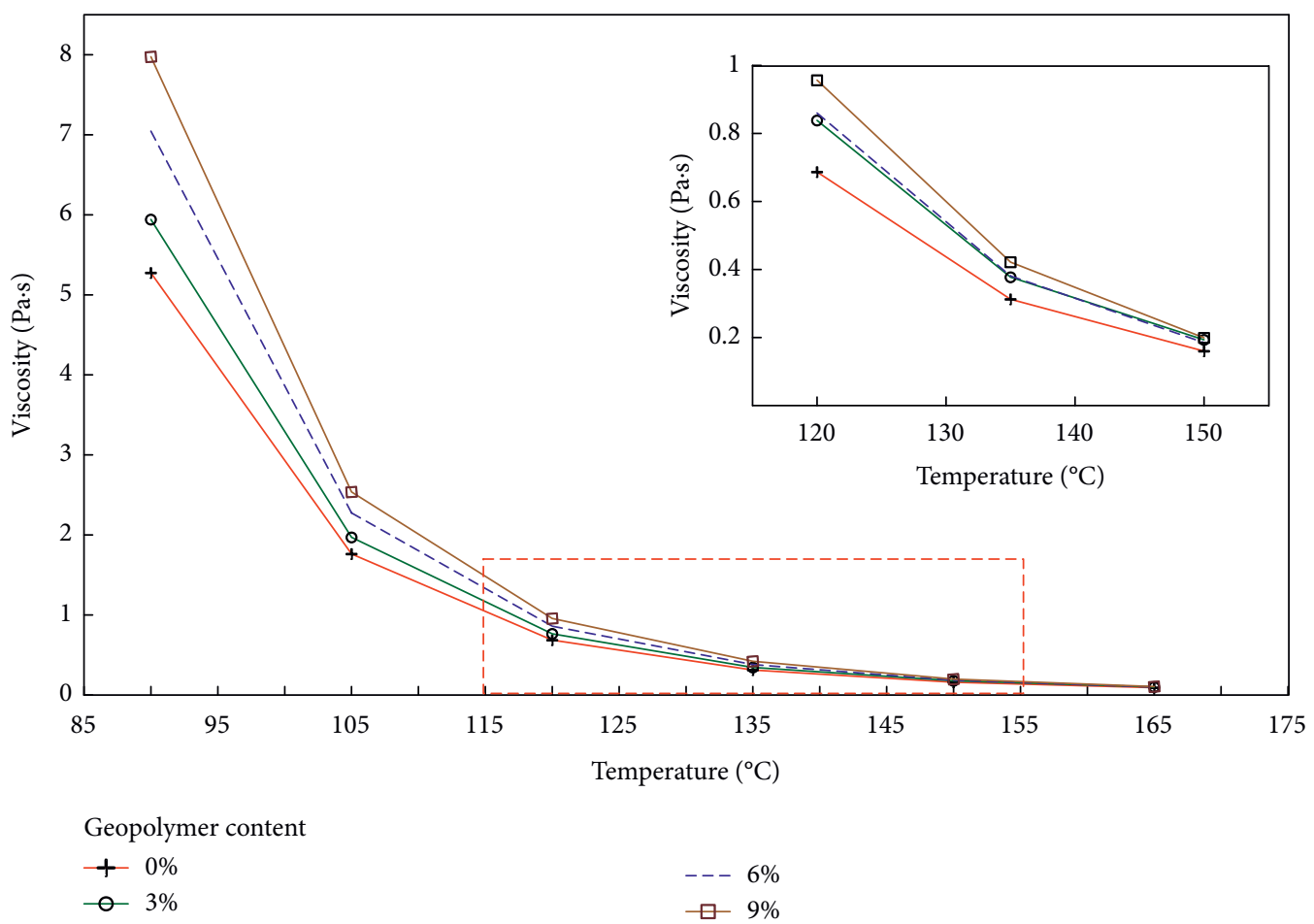

FIGURE 6: Asphalt binder viscosity changing with the temperature at different geopolymer additives.

complex shear modulus. For example, the complex shear modulus at $10 \mathrm{~Hz}$ increased by $127 \%, 214 \%$, and $224 \%$ through adding 3, 6, and 9\% geopolymers, respectively, compared to the virgin binder.
Figure $7(\mathrm{~b})$ shows that the phase angle at $10 \mathrm{~Hz}$ decreased by $2.9 \%, 5.3 \%$, and $6 \%$ due to increasing the geopolymer percentages 3,6 , and $9 \%$, respectively, compared with the virgin binder. This indicates an increase in the elastic response of the 


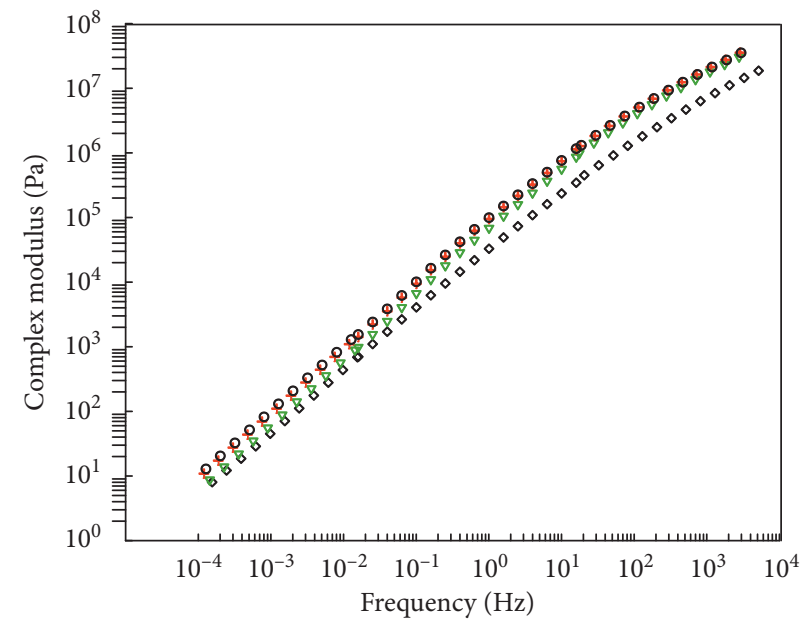

Geopolymer content

$$
\diamond \diamond \diamond 0 \% \quad+++6 \%
$$

(a)

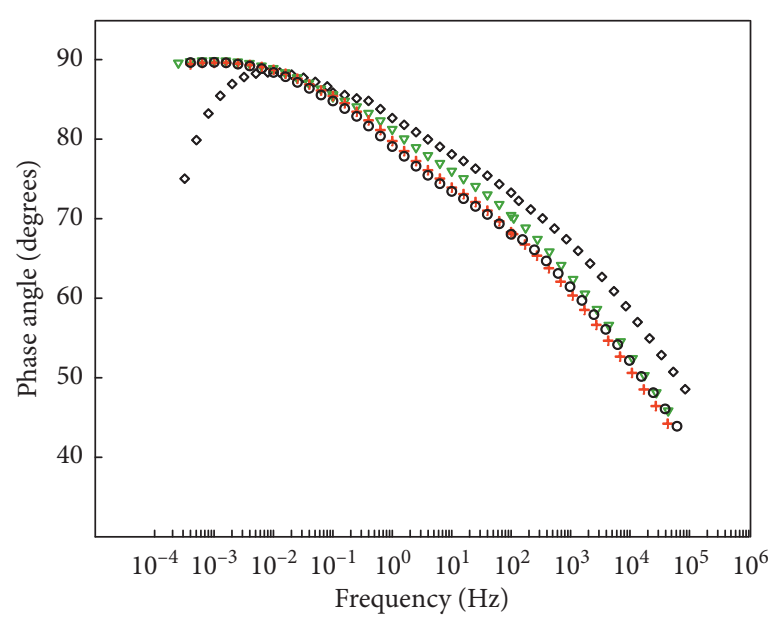

Geopolymer content

$$
\begin{array}{ll}
\diamond \diamond \diamond 0 \% & +++6 \% \\
\nabla \nabla \nabla 3 \% & \circ \circ \circ 9 \%
\end{array}
$$

(b)

Figure 7: Rheological master curve at $35^{\circ} \mathrm{C}$ for (a) complex modulus and (b) phase angle.

modified binder. Therefore, the elasticity of the modified binder increased along with the increasing of geopolymer additives.

4.2.2. Isochronal Plot. Isochronal plots of complex shear modulus $\left(G^{*}\right)$ and phase angle versus temperature at $1 \mathrm{~Hz}$ and $0.1 \mathrm{~Hz}$ of frequency are shown in Figures 8(a) and 8(b). The results presented in Figures 8(a) and 8(b) show that the complex shear modulus significantly increases at various temperatures (59\% average increase) by adding 3\% geopolymers compared with the virgin binder. The statistical $t$ test resulted in a $P$-value of 0.003 . Therefore, the addition of $3 \%$ geopolymers results in a statistically significant increase in complex shear modulus with a confidence level of $95 \%$. However, the insignificant difference is noticed by comparing the complex modulus at $6 \%$ and $9 \%$ geopolymer modified samples compared with the $3 \%$ geopolymermodified. The $P$-values for the $6 \%$ and $9 \%$ geopolymer modified compared with the $3 \%$ are 0.098 and 0.104 , respectively. This indicates that the temperature susceptibility is improved. Previous research literature reported temperature susceptibility increase for elastomer modified binders such as epoxidized natural rubber [28] and styrene butadiene styrene (SBS) [1].

4.2.3. Rutting Factor. Rutting is a permanent deformation which occurs at temperatures higher than $40^{\circ} \mathrm{C}$, leading to ruts in the direction of traffic and can be relevant to the viscosity of the asphalt binder [36]. Figure 9 shows the effect of temperature on the rutting factor $\left(G^{*} / \sin \delta\right)$, which represents a measure of the high-temperature stiffness of the asphalt binder's response to repeated load application at high temperatures. According to the Superpave specification, the rutting factor must be a minimum $1.0 \mathrm{kPa}$ for the unaged binder at $10 \mathrm{rad} / \mathrm{sec}$. This specification is set to minimize the contribution of the asphalt binder to rutting. The results showed that the rutting factor increased by increasing the geopolymer additives which indicates that rutting resistance is improved. The same result for different binder modifiers is also recorded in previous studies [28, 37]. For example, the rutting factor at $58^{\circ} \mathrm{C}$ increased by $22 \%$, $58.2 \%$, and $86.6 \%$ through adding 3,6 , and $9 \%$ of geopolymers by mass respectively, compared with the virgin binder.

4.3. Effects of Geopolymer on Performance Grading. Figures 10(a) and 10(b) show the results of failure temperature obtained from the DSR-grading test. Figure 10(a) shows that the virgin binder has the lowest failure temperature nearly $60.6^{\circ} \mathrm{C}$ compared with geopolymer-modified binder with various percentages. Addition of $3 \%, 6 \%$, and $9 \%$ of geopolymers resulted in an increase of $1.98 \%, 5.78 \%$, and $8.58 \%$ in the failure temperature, respectively. This indicates that the geopolymer could be used to increase the high-temperature grading of asphalt binder. Figure 6(b) shows the results of $9 \%$ modified binder with curing time 2 , 7 , and 14 days. The figure shows that failure temperature for 2, 7, and 14-day curing time exceeded that of the virgin binder by $8.58 \%, 14.2 \%$, and $15.2 \%$, respectively.

4.4. Effects of Geopolymer on the Microstructure of the Binder. ESEM technology was used to observe the polymer-modified asphalt binder microstructure [31, 38]. Stangl et al. [38] used ESEM to investigate the microstructure of asphalt binder with and without modifiers in aged and unaged conditions. The results indicated that aging has a significant effect on the microstructure of asphalt binder, whereby RTFOT-aging caused the network structures to become coarser. Meanwhile, Mikhailenko et al. [30] noted that the denser the 


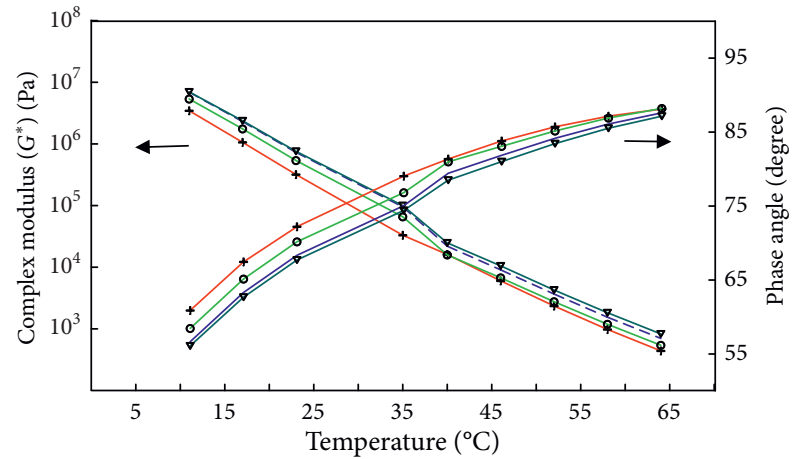

Geopolymer content

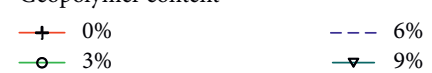

(a)

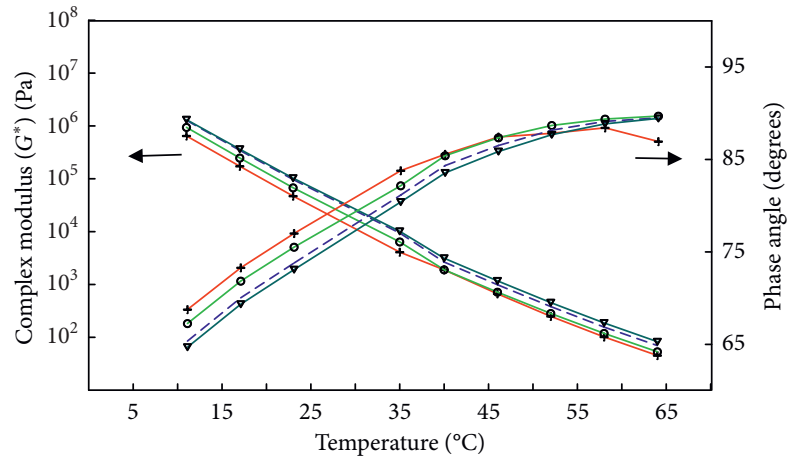

Geopolymer content

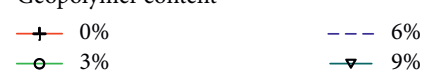

(b)

Figure 8: Isochronal plots of the complex modulus and phase angle at (a) $1 \mathrm{~Hz}$ and (b) $0.1 \mathrm{~Hz}$.

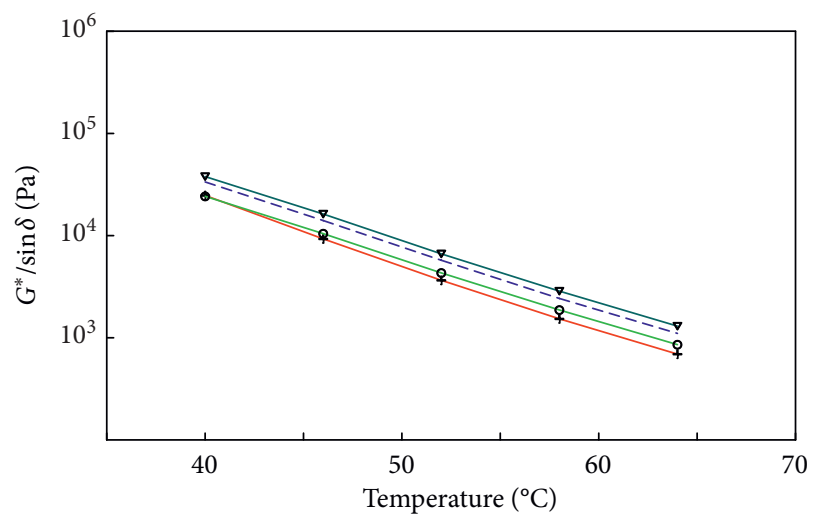

Geopolymer content

$$
+0 \%+6 \%
$$

FIGURE 9: Temperature effect on rutting factor $\left(G^{*} / \sin \delta\right)$.

structure of the fibrils in ESEM imaging, the stiffer the binder is.

In this investigation, ESEM was used to study the microstructure of asphalt binder with different percentages of geopolymer, 3, 6 and 9\%. It is noted that the microstructure of the asphalt binder with $0 \%$ of geopolymer matches the microstructure reported by Mikhailenko et al. [39]; whereas, there is no significant effect of adding 3, 6, and $9 \%$ of geopolymer on the structure of the fibrils in ESEM imaging. In addition, the nanoparticles of the geopolymer were observed under ESEM, as shown in Figure 11. The examination of the ESEM images indicates that the nanoparticles are well dispersed in the binder, and that the microstructures of the binders with 3, 6, and 9\% of geopolymer are quite homogeneous without any visible agglomerations of the geopolymers in the binder.

4.5. Economic and Environmental Effects of Geopolymer. Because of its critical impact on the growth of countries' economics, governments tend to facilitate considerable budgets to improve road-infrastructures. As a result of its severe weather and high traffic load conditions, it is worth nothing that Canada spends millions annually for maintenance of deteriorated pavements for road-infrastructure. Asphalt binder is the world's most commonly used pavement materials, however, is facing several highly sensitive financial and environmental issues. The manufacture of asphalt binder consumes a lot of energy that involves the emission of $\mathrm{CO}_{2}$ into the atmosphere. Greenhouse gas (GHG) emissions must be decreased 50 to $80 \%$ by 2050 in order to limit the global temperature increase to $2^{\circ} \mathrm{C}$ which is considered a challenge to achieve reductions of this magnitude [40]. Meanwhile, Ma et al. [41] noted that reducing (GHG) emission from the construction of asphalt pavement should be focused on the manufacturing stage of raw materials and the mixing process of asphalt concrete. Thus, reducing the usage of the high amount of asphalt binder and decreasing the energy amount during the preparation of hot mix asphalt would have potential financial and environmental effects. Recently, there is a tendency to enhance the asphalt rheological properties using by-product and waste materials that have increased the world over in the last few decades.

It is well known, however, that the potential development of geopolymer has a significant effect on reducing waste and by-product materials, such as fly ash, red mud, mine waste, and blast furnace slag. Into the bargain, using geopolymer as an asphalt modifier has proven its efficiency to improve the rheological properties of asphalt binders thereby enhancing the rutting resistance that results in a reduction of pavement deterioration. Consequently, the reduction in the $\mathrm{CO}_{2}$ emission increases, as a result of decreasing in the production amount of asphalt binder. Thus, the geopolymers have significant economical and environmental impacts on the construction of asphalt pavement. Table 3 summarizes the effect of the geopolymer contents on the viscosities; at 135 and $165^{\circ} \mathrm{C}$, and the compaction and mixing temperature ranges of asphalt mixture. 


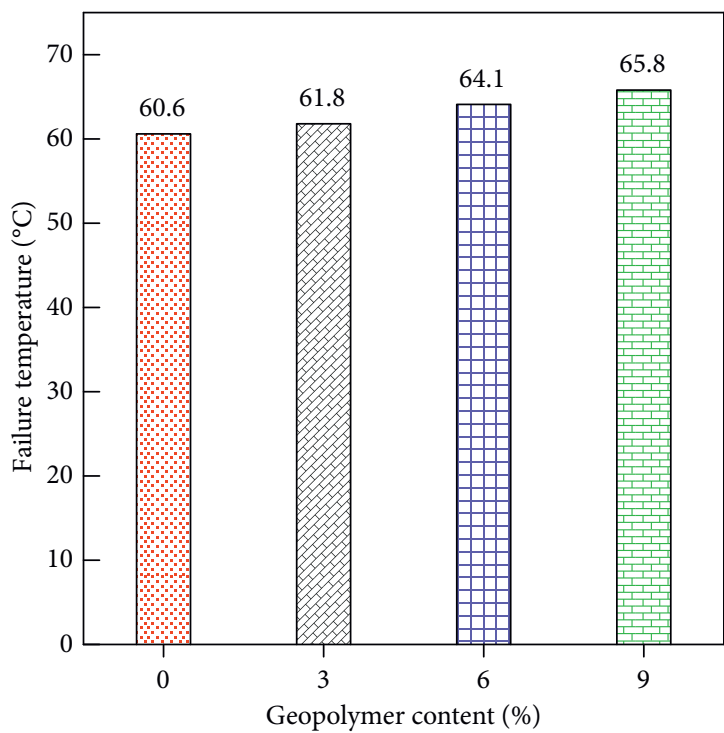

(a)

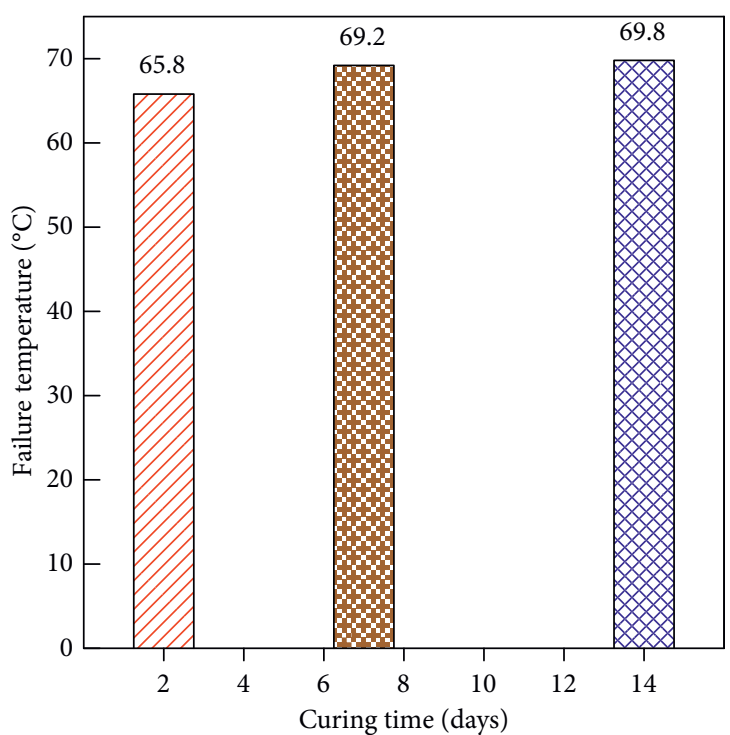

(b)

FIGURE 10: Effects of geopolymer on performance grading, (a) effects of geopolymer additives, (b) effects of curing time on 9\% of geopolymer.

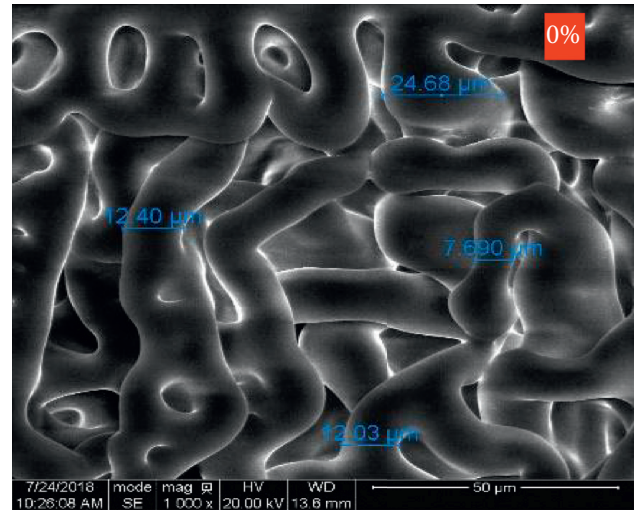

(a)

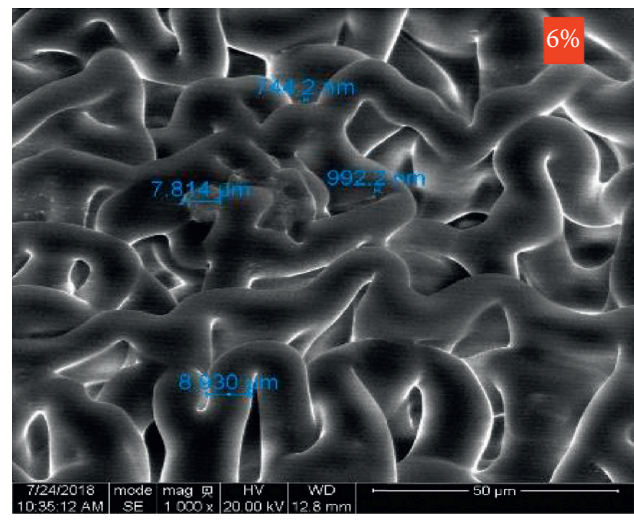

(c)

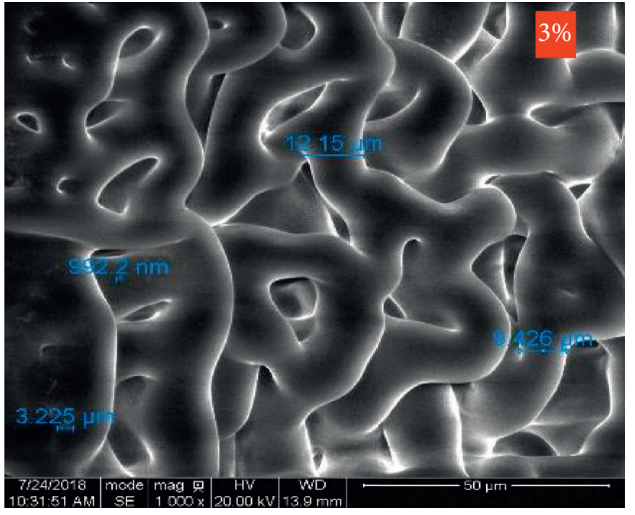

(b)

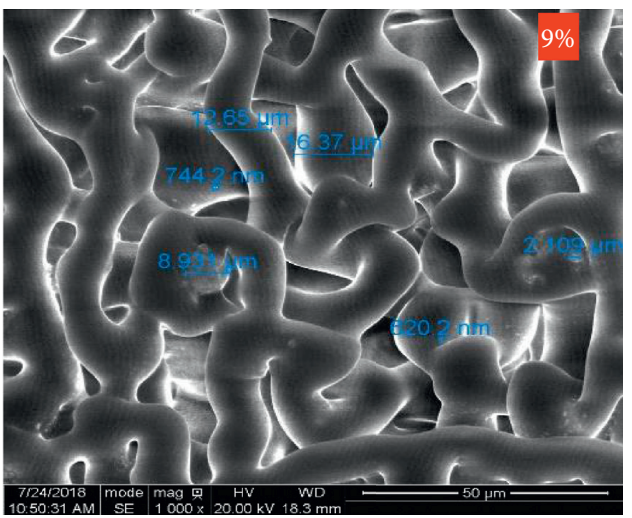

(d)

Figure 11: ESEM observation of different percentage of geopolymer.

The results revealed a minor effect on the compaction and mixing temperature ranges for modified asphalt binder; in comparison with a virgin asphalt binder. However, a slight increase is observed in temperature of compaction and mixing processes for modified asphalt binder, for the curing times; for $9 \%$ of geopolymer at 7 and 14 days. In overall, we 
TABLE 3: Geopolymer effects on compaction and mixing temperature.

\begin{tabular}{|c|c|c|c|c|c|}
\hline \multirow{2}{*}{$\begin{array}{l}\text { Geopolymer } \\
\text { content (\%) }\end{array}$} & \multirow{2}{*}{$\begin{array}{c}\text { Curing } \\
\text { time (days) }\end{array}$} & \multicolumn{2}{|c|}{ Viscosity $(\mathrm{Pa} \cdot \mathrm{s})$} & \multirow{2}{*}{ Compaction range $\left({ }^{\circ} \mathrm{C}\right)$} & \multirow{2}{*}{$\begin{array}{l}\text { Mixing } \\
\text { range }\left({ }^{\circ} \mathrm{C}\right)\end{array}$} \\
\hline & & $@ 135^{\circ} \mathrm{C}$ & $@ 165^{\circ} \mathrm{C}$ & & \\
\hline 0 & 2 & 0.313 & 0.1 & $135-140$ & $148-154$ \\
\hline 3 & 2 & 0.345 & 0.1 & $138-142$ & 149-154 \\
\hline \multirow[t]{2}{*}{6} & 2 & 0.381 & 0.1 & $138-143$ & $149-154$ \\
\hline & 2 & 0.422 & 0.106 & $140-144$ & $150-155$ \\
\hline \multirow[t]{2}{*}{9} & 7 & 0.523 & 0.137 & $144-148$ & $154-160$ \\
\hline & 14 & 0.508 & 0.135 & $144-148$ & $154-159$ \\
\hline
\end{tabular}

can draw the conclusion that the geopolymer application in asphalt binder has minor effects on the compaction and mixing temperatures which imply that there is a minor impact on the energy-consuming during compaction and mixing processes for asphalt mixtures.

\section{Conclusion}

Geopolymer was used in many disciplines such as soil and concrete to develop the mechanical properties rapidly and to improve the high fire resistance property. However, the geopolymer is not widely used to enhance the rheological properties of asphalt binder or mixture. Geopolymer could be used as a sustainable and greener alternative to other asphalt modifiers due to its low carbon dioxide footprint and effective by-products/waste better recycling capacity. This paper presented a laboratory study to investigate the effects of geopolymer content on the rheological and microstructure properties of asphalt binder. The following conclusions have been drawn:

(i) Geopolymer additives had a notable impact on the rheological behavior of asphalt binder. It increased the temperature susceptibility by $1.98 \%, 5.78 \%$, and $8.58 \%$ through adding 3,6, and $9 \%$ geopolymers, respectively. The shear modulus of the modified asphalt binder was increased, and the phase angle was reduced through adding 3, 6, and $9 \%$ geopolymers.

(ii) The rutting factor, at $10 \mathrm{rad} / \mathrm{sec}$ and at $58^{\circ} \mathrm{C}$, increased by $22 \%, 58.2 \%$, and $86.6 \%$ through adding 3 , 6, and $9 \%$ of geopolymers by mass of the binder respectively, compared with the virgin binder which indicates that rutting resistance is improved.

(iii) Geopolymer gained its ultimate properties during the first 7 days, and the curing time crucially impacts the geopolymerization process. The highest increase of failure temperature was for 7- and 14day curing time with an improvement of 14.2 and $15.2 \%$, respectively which indicates that the geopolymer could be used to increase the high-temperature grading of asphalt binder.

(iv) The nanoparticles appear to be well dispersed in the binder. The use of geopolymer does not seem to affect the microstructure of the binder.

\section{Data Availability}

The data used to support the findings of this study are available from the corresponding author upon request. All tests were performed in the Centre for Pavement and Transportation Technology (CPATT), University of Waterloo, under supervision of Prof. Hassan Baaj.

\section{Conflicts of Interest}

The authors declare that they have no conflicts of interest.

\section{References}

[1] G. Airey, "Rheological properties of styrene butadiene styrene polymer modified road bitumens," Fuel, vol. 82, no. 14, pp. 1709-1719, 2003.

[2] H. Baaj, H. Di Benedetto, and P. Chaverot, "Effect of Binder Characteristics on Fatigue of Asphalt Pavement Using an Intrinsic Damage Approachffect of binder characteristics on fatigue of asphalt pavement using an intrinsic damage approach," Road Materials and Pavement Design, vol. 6, no. 2, pp. 147-174, 2005.

[3] M. Aurilio, P. Mikhailenko, H. Baaj, and L. Polikakos, "Properties of asphalt binders with increasing SBS polymer modification," in Proceedings of the 5th International Symposium on Asphalt Pavement and Environment (APE), Padua, Italy, September 2019.

[4] S. Saoula, K. A. Mokhtar, H. Haddadi, and E. Ghorbel, "Improvement of the stability of a modified bituminous binders within eva," International Journal of Applied Engineering Research, vol. 3, no. 4, pp. 575-584, 2008.

[5] S. Liu, W. Cao, J. Fang, and S. Shang, "Variance analysis and performance evaluation of different crumb rubber modified (CRM) asphalt," Construction and Building Materials, vol. 23, no. 7, pp. 2701-2708, 2009.

[6] S. F. Brown, "Discussion: mechanical properties of bituminos materials for pavement design," Journal of International Asphalt Technology, vol. 35, pp. 11-13, 1989.

[7] F. Moreno-Navarro, M. Rubio-Gámez, E. Tomás-Fortún, F. Valor-Hernández, and A. Ramírez-Rodriguez, "Evaluation of the fatigue macro-cracking behavior of crumb rubber modified bituminous mixes," Materiales de Construcción, vol. 64, no. 315, p. e027, 2014.

[8] F. Cheriet, K. Soudani, and S. Haddadi, "Influence of natural rubber on creep behavior of bituminous concrete," Procedia-Social and Behavioral Sciences, vol. 195, pp. 2769-2776, 2015.

[9] M. N. Borhan, F. Suja, A. Ismail, and R. A. Rahmat, "Used cylinder oil modified cold mix asphalt concrete," Journal of Applied Science, vol. 7, no. 22, pp. 3485-3491, 2007. 
[10] M. N. Borhan, A. Ismail, and R. A. Rahmat, "Evaluation of Palm oil Fuel ash (POFA) on asphalt mixture," Australian Journal of Basic and Applied Sciences, vol. 4, no. 10, pp. 5456-5463, 2010.

[11] J. Davidovits, "Geopolymers: inorganic polymeric new materials," Journal of Thermal Analysis, vol. 37, no. 8, pp. 1633-1656, 1991.

[12] G. Görhan and G. Kürklü, "The influence of the $\mathrm{NaOH}$ solution on the properties of the fly ash-based geopolymer mortar cured at different temperatures," Composites Part B: Engineering, vol. 58, pp. 371-377, 2014.

[13] R. Shadnia, L. Zhang, and P. Li, "Experimental study of geopolymer mortar with incorporated PCM," Construction and Building Materials, vol. 84, pp. 95-102, 2015.

[14] J. Davidovits, "Global warming impact on the cement and aggregates industries," World Resource Review, vol. 6, no. 2, pp. 263-278, 1994.

[15] J. T. Gourley and G. B. Johnson, "Developments in geopolymer precast concrete," in Proceedings of the International Workshop on Geopolymers and Geopolymer Concrete, Perth, Australia, July 2005.

[16] S. E. Wallah and B. V. Rangan, Low-Calcium Fly Ash-Based Geopolymer Concrete: Long-Term Properties, Curtin University of Technology, Perth, Australia, 2006.

[17] B. Rangan, "Fly ash- based geopolymer concrete," in Proceedings of the International Workshop on Geopolymer Cement and Concrete, Mumbai, India, December 2010.

[18] J. Davidovits, Geopolymer Chemistry and Applications, Institut Géopolymère, Saint-Quentin, France, 4th edition, 2015.

[19] H. E. Elyamany, A. E. M. Abd Elmoaty, and A. M. Elshaboury, "Magnesium sulfate resistance of geopolymer mortar," Construction and Building Materials, vol. 184, pp. 111-127, 2018.

[20] D. M. J. Sumajouw, D. Hardjito, S. E. Wallah, and B. V. Rangan, "Fly ash-based geopolymer concrete: study of slender reinforced columns," Journal of Materials Science, vol. 42, no. 9, pp. 3124-3130, 2007.

[21] N. Cristelo, S. Glendinning, T. Miranda, D. Oliveira, and R. Silva, "Soil stabilisation using alkaline activation of fly ash for self compacting rammed earth construction," Construction and Building Materials, vol. 36, pp. 727-735, 2012.

[22] P. Sukmak, S. Horpibulsuk, S.-L. Shen, P. Chindaprasirt, and C. Suksiripattanapong, "Factors influencing strength development in clay-fly ash geopolymer," Construction and Building Materials, vol. 47, pp. 1125-1136, 2013.

[23] N. Tang, Z. Deng, J.-G. Dai, K. Yang, C. Chen, and Q. Wang, "Geopolymer as an additive of warm mix asphalt: preparation and properties," Journal of Cleaner Production, vol. 192, pp. 906-915, 2018.

[24] ASTM, Standard Specification for Coal Fly Ash and Raw or Calcined Natural Pozzolan for Use in Concrete, ASTM, West Conshohocke, PA, US, 2018.

[25] J. T. Gourley, "Geopolymers; opportunities for environmentally friendly construction materials," in International Conference and Exhibition on Adaptive Materials for a Modern Society, The Institute of Materials Engineering Australasia Ltd., Melbourne, Australia, 2003.

[26] H. Xu and J. S. J. Van Deventer, "The geopolymerisation of alumino-silicate minerals," International Journal of Mineral Processing, vol. 59, no. 3, pp. 247-266, 2000.

[27] X. Lu and U. Isacsson, "Rheological characterization of styrene-butadiene-styrene copolymer modified bitumens,"
Construction and Building Materials, vol. 11, no. 1, pp. 23-32, 1997.

[28] R. A. Al-Mansob, A. Ismail, A. N. Alduri, C. H. Azhari, M. R. Karim, and N. I. M. Yusoff, "Physical and rheological properties of epoxidized natural rubber modified bitumens," Construction and Building Materials, vol. 63, pp. 242-248, 2014.

[29] T. R. Clyne, X. Li, M. O. Marasteanu, and E. L. Skok, Dynamic and Resilient Modulus of Mn/DOT Asphalt Mixtures, Minnesota Department of Transportation, Saint Paul, MN, USA, 2003.

[30] P. Mikhailenko, C. Kou, H. Baaj et al., "Comparison of ESEM and physical properties of virgin and laboratory aged asphalt binders," Fuel, vol. 235, pp. 627-638, 2019.

[31] P. Mikhailenko, C. Kou, H. Baaj, and S. Tighe, "Observation of polymer modified asphalt microstructure by ESEM," in Proceedings of the 6th International Conference on Engineering Mechanics and Materials, Canada, Vancouver, May 2017.

[32] A. K. Swamy, U. D. Rongali, and P. K. Jain, "Effect of HDPEH polymer on viscoelastic properties of SBS modified asphalt," Construction and Building Materials, vol. 136, pp. 230-236, 2017.

[33] M. A. Taylor and N. P. Khosla, Stripping of Asphalt Pavements: State of the Art, Transportation Research Record Journal of the Transportation Research Board, Washington, DC, USA, 1983.

[34] L. Zhang, S. Ahmari, and J. Zhang, "Synthesis and characterization of fly ash modified mine tailings-based geopolymers," Construction and Building Materials, vol. 25, no. 9, pp. 3773-3781, 2011.

[35] S. Ahmari, L. Zhang, and J. Zhang, "Effects of activator type/ concentration and curing temperature on alkali-activated binder based on copper mine tailings," Journal of Materials Science, vol. 47, no. 16, pp. 5933-5945, 2012.

[36] A. Adedeji, T. Grünfelder, F. S. Bates, C. W. Macosko, M. Stroup-Gardiner, and D. E. Newcomb, "Asphalt modified by SBS triblock copolymer: structures and properties," Polymer Engineering \& Science, vol. 36, no. 12, pp. 1707-1723, 1996.

[37] A. Khadivar and A. Kavussi, "Rheological characteristics of SBR and NR polymer modified bitumen emulsions at average pavement temperatures," Construction and Building Materials, vol. 47, pp. 1099-1105, 2013.

[38] K. Stangl, A. Jäger, and R. Lackner, "Microstructure-based identification of bitumen performance," Road Materials and Pavement Design, vol. 7, no. 1, pp. 111-142, 2006.

[39] P. Mikhailenko, H. Baaj, C. Kou et al., "ESEM microstructural and physical properties of virgin and laboratory aged bitumen," in RILEM 252-CMB-Symposium on Chemo Mechanical Characterization of Bituminous Materials, pp. 150-155, Springer, Cham, Switzerland, 2018.

[40] A. I. Kay, R. B. Noland, and C. J. Rodier, "Achieving reductions in greenhouse gases in the US road transportation sector," Energy Policy, vol. 69, pp. 536-545, 2014.

[41] F. Ma, A. Sha, R. Lin, Y. Huang, and C. Wang, "Greenhouse gas emissions from asphalt pavement construction: a case study in China," International Journal of Environmental Research and Public Health, vol. 13, no. 3, p. 351, 2016. 